\title{
IMAGENS NEGOCIADAS: O EXPERIMENTAL NO CINEMA
}

\author{
Andréa França
}

Pontifícia Universidade Católica/RJ

\section{Resumo}

Discute-se os desafios da tecnologia no campo das artes da imagem, tendo como foco dois documentários brasileiros que utilizam o vídeo digital menos para pensar o mundo ao qual se referem do que explorar as imagens que o constituem e os dispositivos (linhas de encaminhamento que implicam o espectador/personagem em determinadas relações físicas, subjetivas, cognitivas) que as acompanham. A pessoa é para o que nasce e Passaporte Húngaro são elaborados a partir daquilo que se quer filmar e não de pressuposições do diretor ou de realidades que os filmes pretensamente representariam. A crescente mediatização do cotidiano, através sobretudo da mídia televisiva, traz questões agudas para o campo do documentário que se depara cada vez mais com um mundo que já se dá como imagem, que detém um saber sobre o que significa "ser filmado". Roberto Berliner e Sandra Kogut dialogam com essa situação à medida que fazem da câmera um catalisador de comportamento, um dispositivo que produz outra imagem e outro real.

Palavras-chave: filmes-documentário; vídeo digital; novas linguagens.

\begin{tabular}{|l|l|l|l|l|}
\hline Ilha do Desterro & Florianópolis & $n^{\circ} 51$ & p. 147-163 & jul./dez. 2006 \\
\hline
\end{tabular}


Com a aparição e a difusão da tecnologia digital, a distância entre a realização de um filme e o espectador vem se reduzindo bastante. A quantidade de filmes documentários que tem chegado aos festivais nacionais, por conta dessa nova tecnologia, é surpreendente quando se compara com uns dez anos atrás. Talvez se possa falar em uma nova geração de documentaristas que ganha força a partir de meados dos anos 90, dentro de uma tendência de fome de real e de vínculo social com o mundo. Nunca se produziu tantos documentários, nunca se dispôs de tantos suportes e mídias, nunca um campo imagético fomentou tamanha variação de procedimentos e estilos. É nesse sentido que podemos dizer que o campo do documentário constitui-se hoje como uma ampla rede de produções a partir de diálogos com sua história e estilos, o que implica continuidades, rupturas, metamorfoses. São os métodos clássicos revisitados, a postura de invisibilidade da equipe do Cinema Direto, o modo interativo do Cinema Verdade, os filmes de montagem que dão novos sentidos aos arquivos audiovisuais e, ainda, as experiências radicalmente afirmativas do gesto de negociação entre o documentarista e a realidade, a dimensão afetiva, singular e poética desse gesto (que nos interessa aqui).

A discussão sobre vídeo digital e cinema é também a discussão sobre os desafios da tecnologia no mundo das artes da imagem. Não se trata de fazer a apologia da tecnologia do vídeo como uma ruptura radical, dentro dos sistemas de representação, da qual seríamos necessariamente testemunhas e atores. A retórica de ostentação da técnica caminha junto com a crença em uma nova estética, uma nova forma de linguagem, o que soa ingênuo à medida que faz tábula rasa da própria história das formas de representação, alardeada por discursos da "inovação" em momentos de transição tecnológica, discursos que pressupõem a ideologia do progresso contínuo e da ruptura completa com o que já existe em termos de representação. E, para além do problema da retórica tecnológica, outras questões se colocam, de natureza teórica, como atentam alguns pesquisadores: ${ }^{1}$ quando falamos em vídeo estamos falando de uma técnica ou de uma linguagem? De um proces- 
so ou de uma obra? De um meio de comunicação ou de uma arte? De uma imagem ou de um dispositivo?

O circuito eletrônico da imagem do vídeo permite que as imagens do mundo apareçam em sua duração própria, transmitida à distância, ao vivo e multiplicada: ver o mesmo acontecimento, onde quer que haja receptores, em tempo real e alhures. Diferente da imagem cinematográfica (dotada de uma materialidade que é a película, com seus fotogramas, enquanto imagem prévia ao ato perceptivo da projeção), a imagem eletrônica (o vídeo e a televisão) não possui a concretude de uma imagem material que seria visível na sua base, como a fotografia, o filme ou a pintura. Sua unidade mínima visível é o ponto de varredura, uma trama de linhas e pontos numa tela fosforescente que mais parece uma "chuva de elétrons". ${ }^{2} \mathrm{E}$ alguns artistas vão potencializar esta desmaterialização da imagem eletrônica, a ponto de afirmar que "o vídeo não é nada mais do que o tempo, somente o tempo" ou ainda que é o "terminal ilimitado de todas as imagens do mundo, de todas as imagens passadas, presentes e futuras; ${ }^{3}$ ou ainda, explorar o aspecto de transmissão ao vivo do dispositivo, que são as instalações baseadas em "circuito fechado" onde a câmera restitui ininterruptamente a imagem específica de sua própria situação. Philippe Dubois vai afirmar que o vídeo tem uma natureza efetivamente bifronte: por um lado, é uma imagem a mais, ao lado de outras formas de imagem como a pintura, a fotografia, o cinema, a televisão, a imagem de síntese. Por outro, o vídeo é processo, puro dispositivo, sistema de circulação de uma informação qualquer, um meio de comunicação independente do seu resultado visual e do conteúdo das mensagens que ele possa veicular e, nesse sentido, está bem próximo à linhagem histórica do telefone ou do telégrafo. Portanto, entre o domínio do poético-artístico e o circuito de comunicação-informação, transita o vídeo numa "posição difícil, instável, ambígua: ele é a um só tempo objeto e processo, imagem-obra e meio de transmissão, nobre e ignóbil, privado e público. Ao mesmo tempo pintura e televisão". ${ }^{4}$ Gostaria de destacar neste artigo o modo como esta ambivalência será potencializada positivamente em alguns filmes brasileiros recentes. 
Antes disso, seria importante lembrar que a palavra vídeo é, dentro de uma abordagem etimológica, um verbo (vídeo, do latim videre, "eu vejo") que engloba todo o ato de ver, todo o ato de olhar, que está na base das formas de representação visual, na base de todas as artes que convocam a experiência perceptiva junto com os demais sentidos; ${ }^{5}$ assim é que o vídeo, além de objeto/obra, pode ser uma forma que pensa a televisão, o cinema, a pintura, o computador (o videogame, o videoclipe, a videoarte, a videoinstalação). Vale lembrar que a modernidade cinematográfica já procurava extrair vigorosos agenciamentos entre a televisão e o cinema. E Jean-Luc Godard inaugurou o percurso original de articular cinema e vídeo (Numéro deux) 1975, Six foix deux /1976, France tour détour deux enfants/1977-78), já na primeira metade dos anos $70 .{ }^{6}$ É neste enfrentamento estratégico que o cinema pôde pensar a problemática da vigilância (Fritz Lang), da atualidade (Roberto Rosselini), da (des)programação (Orson Welles), temas imprescindíveis para uma reflexão sobre a televisão.

A leveza, o baixo custo da tecnologia do vídeo, essa forma a meio caminho entre o regime das imagens e aquilo que é puro dispositivo, sistema de circulação de informação, tem estimulado de um lado a videoarte, em suas formas múltiplas e, de outro, o documentário, com todas as suas estratégias e procedimentos de representação; esse estímulo permite que Jean-Claude Bernardet possa perceber uma tendência, como parte de um movimento dos mais estimulantes do documentário recente, onde "a documentação tende a se tornar o registro da busca". ${ }^{7}$ Não se trata, como nos documentários mais convencionais, de uma situação que pré-existe ao filme, mas de uma realidade que é criada no ato mesmo de filmar, em função justamente da filmagem, de modo a acentuar o aspecto de ensaio, de experimentação, de pesquisa, de indeterminação, de negociação diante do mundo. O registro de uma busca, como procedimento de filmagem, vai permitir a realização de filmes sensíveis, singulares, distantes de teorias ou pré-conceitos sobre questões complexas como exclusão social, identidade, pobreza, laços familiares. 
A produção atual de filmes brasileiros, especialmente documentários, tem possibilitado um senso de inovação bastante instigante. Preto e Branco (Carlos Nader, 2003), Do outro lado do rio (Lucas Bambozzi, 2004), Passaporte húngaro (Sandra Kogut, 2001), 33 (Kiko Goifman, 2003), Rua de mão dupla (Cao Guimarães, 2003), A pessoa é para o que nasce (Roberto Berliner, 2004), O chapéu do meu avô (Julia Zakia, 2004), para citar alguns, são imagens cujos modos de representação variam entre a proposta de extrair uma trama complexa de discursos sobre o preconceito racial no Brasil (Preto e branco), explorar o imaginário da fronteira através de um "mergulho" na espessura da imagem (Do outro lado do rio), afirmar um "eu" em contato, fluido que, ao falar de si, também quer falar do outro (Passaporte húngaro, $O$ chapéu do meu avô, 33), partir do campo da videoarte para inverter o problema do "outro" no campo do documentário (Rua de mão dupla que, primeiramente, foi uma instalação exibida na Bienal de São Paulo), escrever em imagens e sons a experiência da cegueira de modo a fazer nascer acontecimentos na e pela imagem (A pessoa é para o que nasce). Talvez se possa dizer que o vídeo tem estimulado diferentes formas de representação das imagens, precisamente por ser um domínio que não designa imediatamente um meio de representação (um objeto com um corpo próprio), mas uma forma capaz de fomentar múltiplos modos de visualidade para a imagem, segundo Dubois, um meio que pensa não tanto o mundo, mas as imagens que o compõem e os dispositivos que as acompanham.

Se tais documentários inovam nas formas de linguagem é porque as realidades que vêm à tona são resultado de determinados procedimentos de filmagem elaborados justamente a partir daquilo que se quer filmar, seja uma busca, seja um universo social (como no cinema de Eduardo Coutinho), seja uma deficiência física, seja o imaginário da fronteira como esperança de nova vida. O que interessa a esses cinemas não é refletir a realidade e tampouco obedecer ao que estava previsto em um roteiro: interessa produzir acontecimentos especificamente fílmicos, acontecimentos que não estavam previstos antes da filmagem e que o ato de filmar provoca, intensifica, captura. 
Assim é que tais imagens se mostram sob o risco constante de se desfazer diante das contingências e imprevistos do real; ao criar universos em aberto, universos que se constróem junto com o ato de filmar, tais filmes propõem uma reflexão sobre as imagens do mundo e suas formas de representação.

O documentário A Pessoa é para o que nasce (2004), primeiro longa-metragem de Roberto Berliner, tem como objeto a vida de três irmãs cegas de nascença, que sobrevivem como tocadoras de ganzá pelas ruas de Campina Grande, no interior da Paraíba. ${ }^{8}$ Uma primeira questão seria: como extrair uma imagem de quem nunca pôde ver aquilo que o espectador vê, ou ainda, como se aproximar com uma câmera de quem vê apenas luminosidades, silhuetas, sonoridades, sensações? Questão essencial porque diz respeito ao modo de abordagem desse universo, ao modo como a equipe se introduz e introduz o espectador na vida das três irmãs. Maria, Regina e Conceição não foram "descobertas" por Berliner para o filme; elas já eram conhecidas do diretor desde 1997, durante as filmagens da série para televisão "Som da Rua", sobre músicos brasileiros anônimos. ${ }^{9}$ É nesse período que Berliner as conhece, mas elas já não cantavam mais nas ruas e portanto não possuíam mais os ganzás. A produção providenciou os novos instrumentos e, durante esse período, a equipe teve oportunidade de conversar longamente com as três, surgindo a idéia de fazer um curta-metragem sobre elas. ${ }^{10}$

Essas informações são dadas fragmentariamente pelo filme. Filmado e editado entre 1998 e 2003, essa versão em longa-metragem, realizada com vários suportes, ${ }^{11}$ acompanha os afazeres cotidianos destas mulheres que viveram toda sua vida cantando e tocando ganzá em troca de esmolas nas feiras da região mais pobre do país. Para que o mundo das três cegas, não só factual mas sensorial e poético, possa aos poucos se revelar - ao diretor e ao espectador - não basta ouvir suas histórias de sobrevivência, mostrar o modo com que parentes e vizinhos as ajudam, flagrar uma trama complexa de amor, traições e morte. É necessário fazê-las experimentar - já que estão impossibilitadas de 
ver - o dispositivo da câmera nos seus próprios corpos, e tudo que isso implica de relação física, ativa e, obviamente, inaugural. A primeira parte registra a relação que se estabelece entre elas e a câmera - a câmera acoplada ao corpo e voltada para ele, o manuseio da câmera, a descoberta do cinema, o desejo de "ficar conhecida", de ser famosa -, como se essas imagens quisessem testar se as aproximações entre diretor e personagem se ajustam às armadilhas de um mundo onde o nosso olhar (e do documentarista) não é correspondido, devolvido, partilhado. Existe aqui um diálogo com as iconografias dos clássicos hollywoodianos - Maria deitada na relva como uma "diva", a música épica de Enio Morriconi que acompanha o surgimento das três na abertura -, como se o filme quisesse corresponder ao desejo de cinema das cegas, tornar-se um meio para que elas enfim possam virar "estrelas". É o cinema como uma grande reserva de formas, motivos e mitos, o cinema-reservatório exposto e repensado pelo documentário, pelo vídeo.

A pessoa é para o que nasce revela um mundo extremamente incômodo para o espectador, de difícil fruição: as três não podem administrar o olhar do outro (documentarista e espectador) e essa impotência nos incomoda justamente porque impede uma auto mise-en-scène, isto é, a consciência de ser percebido como imagem e de estabelecer estratégias de encenação, de construção de si. Uma limitação - de olhar o olhar do outro - que produz o inesperado, o que não poderia estar num roteiro (=previsível, planejado, antecipado), que é a entrada em cena do documentarista, capturado pelo próprio dispositivo que criou para dar conta desse universo específico. Tornar-se imagem é o meio encontrado pelo filme de partilhar com elas de um campo comum, talvez o único possível, que é o próprio documentário se constituindo enquanto tal: um processo em aberto, frágil, imprevisível.

Sabemos que as três encontram-se incapazes de administrar (técnica e intelectualmente) a operação para a qual emprestam seu corpo e sua voz. Mas essa situação não é absolutamente nova e representa no limite a experiência e a condição de todo ator de documentário, na medida em que se encontra impossibilitado de administrar sua imagem, 
principalmente na edição. Maria, no entanto, diz que "o cinema tem que ter graça, filmar é bom". Por que? Certamente porque percebe nessa aproximação do diretor a possibilidade, não de uma imagem de si que irá satisfazê-la (e poderia?), mas de uma experiência afetiva e poética, de uma relação sensorial que o filme traduz e intensifica quando incorpora à música das três as sonoridades de Hermeto Pascoal, suas notas dissonantes, quando se interessa pelos detalhes do cotidiano, do passado, das emoções, dos sonhos, criando acontecimentos na e através da imagem - o apagar e acender da luz, os efeitos de montagem - mergulhando na sua textura plástica e sonora.

A segunda parte mostra o efeito-cinema na vida dessas mulheres. A repercussão do curta $A$ Pessoa é para o que nasce faz com que a música delas chegue aos ouvidos do curador do Festival Percpan, Gilberto Gil, transformando-as da noite para o dia em celebridades. Recebem cachês pelas apresentações em meio às várias atrações nacionais e internacionais. É nessa parte que o diretor entra em cena: anuncia para as cegas que vai deixar uma câmera de vídeo no quarto onde elas estão hospedadas, de modo a gravar "tudo" que se passa lá. Assim é que tal imagem funciona (para nós) dentro do regime de vigilância e controle: a câmera como dispositivo declarado de transmissão em tempo contínuo, sem interrupções, instalada no quarto de modo a implicar todos que ali estão numa dinâmica da interioridade, sem contra-campo possível, sem exterior. O espaço off dessa imagem está ali, incorporado à sua própria espessura. Um pouco antes, Maria havia declarado a Berliner que "tinha um amor"... Declaração que não estava prevista e que nem poderia ser antecipada, mas que coloca todo o filme em risco, produzindo questões de natureza estética eética: como continuar filmando a partir do momento que o personagem declara estar apaixonado pelo diretor (pois é disso que se trata), como não interromper tudo, como restabelecer a distância necessária, como fazer enfim para que o filme continue sob o risco constante do real invadir a cena? ${ }^{12}$

A câmera deixada no quarto é o modo encontrado pelo diretor de lidar com o imprevisto da filmagem, do ato de filmar. Ela registra a chegada do diretor e sua necessidade de explicar para as cegas que tem 
mulher, família, etc., de modo a ajustar-se ao movimento de desvelamento (emocional e poético) do próprio documentário e, ainda, garantir uma segurança própria ao mecanismo de "tudo ver, tudo mostrar, nada esconder", típico dos dispositivos de vigilância. Podemos supor que a decisão de deixar uma câmera no quarto delas surgiu depois que o diretor soube do amor de Maria: a câmera fixa fornece à equipe uma espécie de segurança e anteparo para o que há de patético nesse "amor", mas talvez não mais patético do que nossas razões para reconhecê-lo como tal. A câmera-dispositivo registra então o que filme produz, provoca, a urgência absolutamente imprevisível de Berliner tornar-se personagem. A curiosidade enfim se sobrepõe à repulsão.

Na última parte, Berliner volta à Campina Grande, depois de mais de um ano sem vê-las, com o intuito de apreender que transformações essa "fama" teria produzido em suas vidas. A pergunta que fica para o espectador é: o que pode o documentário, o que pode o cinema diante de uma realidade dura, precária, difícil? Pode muito pouco, nada, quase nada? O filme injeta na vida delas a máquina-cinema e tudo que essa relação de sedução e risco pode provocar. Nesse jogo de quatro lados - de um lado, as três irmãs com suas questões pessoais; de outro, o diretor com suas questões pessoais; por trás dele, a questão de saber como estas imagens vão funcionar para o público; por trás delas, o que elas esperam desta operação de filmá-las - o documentário consegue ampliar o lugar das três, lugar efetivamente construído no encontro com o documentarista, na negociação precária, arriscada e sedutora entre o documentarista e a realidade.

Personagem excessivamente filmado, documentado, pensado e recriado pelo cinema brasileiro, desde principalmente os anos 60 (em filmes como Os fuzis, Deus e o Diabo na Terra do Sol, Vidas Secas, Viramundo, no texto-manifesto Estética da Fome, de 1965), "o camponês", "o nordestino" - miserável mas alimentado pela fé mística, massacrado pelo destino porém forte - ressurge aqui a partir de uma interlocução incisiva, de um encontro feito de enfrentamentos, diferenças e aproximações; e Cabra marcado pra morrer (1984) já inaugurava no campo do documentário a escuta atenta e ativa desse outro, elimi- 
nando o tratamento cerimonioso e sacralizado que vai marcar, duas décadas depois, o panorama do documentário brasileiro na relação com o personagem pobre..$^{13}$ Ao estabelecer um diálogo efetivo com as três cegas, A pessoa é para o que nasce nos aproxima delas sem pretender ilustrar uma tese sobre a cegueira nem tampouco aderir aos postulados humanistas de uma arte que subsiste em meio ao sofrimento total e que só resta ao espectador também sofrer, partilhar, deplorar; longe disso, o documentário funciona como um meio para que as cegas possam surgir, agir e reagir, experimentar enfim o cinema enquanto imaginário, reservatório de mitos e formas.

Negociar com os imprevistos da realidade e mostrar/dizer esse gesto de negociação implica recuperar o percurso de diretores e movimentos cinematográficos como o "cinema do vivido" de Pierre Perrault e o "cinema-verdade" de Jean Rouch e Edgar Morin, pois a contribuição desses diretores é justamente ter questionado a imagem do outro (qualé, afinal?), inaugurando essa problematização. Se o documentário hoje retoma esse questionamento, sem negar no entanto a possibilidade de falar do outro, é porque há, entre outras coisas, uma massificação da cultura visual e, nesse processo, uma disputa entre documentário e a televisão globalizada pelos acontecimentos do mundo e por personagens "reais". Mas, como enfatizam alguns estudiosos, não se filma impunemente, e a prática do documentário desloca essa massificação à medida que o procedimento de mostrar o mundo está nas mãos de pessoas concretas: quem filma? quem fala? como irão circular as imagens, esses corpos reais e suas mise-en-scène ${ }^{14}$ Questões que dizem respeito necessariamente ao lugar do espectador: como ele vê, julga o que vê, suas expectativas diante do cinema.

Dentro dessa tendência contemporânea, detectada por Bernardet, onde o documentário tende a se tornar o registro da busca, uma experimentação, Passaporte Húngaro, da realizadora Sandra Kogut, é também interessante. Kogut é o centro do filme ao mesmo tempo que está fora de quadro e não dentro dele. Fora de quadro porque em nenhum momento ela se apresenta como a pessoa que está em busca de um passaporte húngaro. $\mathrm{O}$ que vemos é um pedaço de mão que entrega 
um documento ou assina um papel, um fragmento do rosto que avança no canto do quadro. Figura mais ouvida do que vista, a cineasta brasileira, residente em Paris, utiliza a "câmera subjetiva" para registrar as pessoas com quem ela se relaciona em meio à busca: sua avó, amigos, parentes, funcionários da embaixada e todos que, como ela, solicitam um passaporte húngaro.

Mas o dispositivo da câmera subjetiva não tem o sentido habitual dos filmes de ficção: ela não visa a ampliar a identificação do espectador, operando como se fosse autônoma; ao contrário, a câmera de Kogut quer fazer o espectador experimentar um descompasso próprio a um sujeito que vê e nos mostra o seu campo de visão, a sua narrativa. Trata-se de um dispositivo que afirma o olhar da diretora sob o modo da alteridade (e não da identidade), uma visão com corpo, em contato, que provoca situações e reage a elas, que ao falar de si também fala do mundo.

Filmar a busca por um passaporte húngaro implica lidar com a memória íntima dos seus avós, memória ao mesmo tempo coletiva, evocadora da perseguição aos judeus, às vítimas do nazismo. Memória, enfim, de todos aqueles que, para sair da Europa no final da década de 1930, tiveram a letra Kimpressa em seus passaportes. Tudo indica que foi a partir da gravação das conversas com a avó (austríaca que se tornou húngara com o casamento e que foi obrigada a abandonar a Hungria com o marido, em 1937, vindo para o Brasil), que a cineasta enlaçou seu tema. Como se ela tivesse decidido levar adiante anos depois uma idéia meio abandonada, de modo que "os fatos são também uma cena inventada por Sandra, uma cena cinematográfica, se não uma ficção pelo menos uma ação provocada para ser vivida e filmada por ela" ${ }^{15} \mathrm{O}$ filme registra esse movimento de busca/ação pelos documentos necessários e nos convida para uma viagem interior, privada e íntima que é também uma viagem pelo mundo (França, Brasil, Hungria), pública e política.

Passaporte húngaro não quer absolutamente registrar a busca pelas raízes ou pela identidade perdida: seu interesse é ir além das teorias e dos pré-conceitos sobre identidade. À medida que o documentário incorpora à sua narrativa uma gama de outras vozes, 
línguas (francês, português, húngaro, hebraico, alemão), e personagens, o que vemos são imagens dialogantes, imagens que mantêm o movimento entre o dentro e o fora, o íntimo e o social, o privado e o coletivo. Interessa o processo que envolve a busca. Importa pouco, no final das contas, a aquisição do passaporte, mas importam as histórias contadas pela avó, pelo casal simpático de idosos húngaros, as descobertas feitas ao acaso como a necessidade de falar e ler húngaro para ter um passaporte húngaro. Isso porque a diretora parte do sentimento de não conhecer nada, ou seja, não há um roteiro a seguir ou uma tese a ilustrar - tal como as mazelas de uma brasileira judia, neta de húngaros, que deseja adquirir um passaporte desse país. O que existem são imagens dialogantes, imagens negociadas, que permitem que possamos conhecer alguma coisa da busca de Kogut para além de uma perspectiva autobiográfica ou identitária.

Ao explorar situações, fragmentos de conversas, Kogut nos intima a pensar o que é um sujeito hoje, senão aquele que se forma nos entrelugares, nas fronteiras, na mistura, no processo de ir e vir. E para flagrar essa hibridação, a cineasta precisa marcar sua presença na câmera e na voz, marcar o ato de dialogar através do seu olhar-corpo. No limite, o que a diretora documenta é a sua presença na relação com o outro. Há um sentido que está sempre aberto à interpretação e à interpelação de alguém, e as imagens soltas e reiterativas de estações ferroviárias vazias, bondes, barcos, trens, gente passando, se inscrevem no filme como imagens do entrelugar, das misturas possíveis, da fronteira; ${ }^{16}$ pois o filme mostra que o processo de busca pelo passaporte (=identidade, raízes) envolve diálogo, hibridismo, negociação e reinvenção dos limites entre o espaço e o tempo, o dentro e o fora, ${ }^{17} \mathrm{O}$ privado e o público.

Tanto A Pessoa é para o que nasce como Passaporte húngaro mostram universos que se constróem junto com o ato de filmar, de modo que propõem também uma reflexão sobre as imagens do mundo e suas formas de representação. Ao pesquisar, experimentar, ensaiar outras formas de visibilidade para as imagens de miséria, deficiência física e identidade, tais filmes parecem reconhecer sua ação através da câmera, 
seu papel assertivo, sua parcialidade - que não é a impossibilidade de acesso ao mundo, típica do documentário reflexivo -, sua responsabilidade na construção da realidade por vir. Ambos os filmes se afirmam como o lugar da inscrição da intimidade, de um "eu" encarnado na sua relação afetiva, poética e subjetiva com o mundo.

Há ainda o empreendimento desses trabalhos em vídeo: em Berliner, o cinema enquanto reservatório do imaginário das divas, das grandes estrelas hollywoodianas, se vê assim aludido, interrogado, "exposto" no e pelo vídeo; em Kogut, a pequena câmera de vídeo digital reforça o caráter de escrita pessoal e de imagem-testemunha, de modo a realizar o sonho indistinto da "câmera-caneta", de Alexandre Astruc, da experiência que pode ser escrita e vivida, tudo ao mesmo tempo: "...gravação numa fita de imagem-som dos meandros e do lento ou frenético desenrolar de nosso universo imaginário, o cinema-confissão, ensaio, revelação, mensagem, psicanálise, obsessão, máquina de ler as palavras e as imagens de nossa paisagem pessoal". ${ }^{18}$

Passaporte húngaro dialoga sobretudo com o imaginário sensacionalista e belicoso do purismo cultural, da condenação das misturas, de acontecimentos mediados que primam por polarizar civilizações e culturas; é um imaginário fabricado com freqüência pelas notícias quando naturalizam hostilidades ao invés de historicizar as diferenças, quando não colocam os conflitos dentro de uma perspectiva histórica, econômica, política; este imaginário espetacularizado se vê, pelo vídeo de Kogut, repensado e interrogado a partir de uma outra dimensão, dialógica, negociada e, sem sombra de dúvida, necessária.

Vivemos múltiplas dimensões de um pensamento visual cada vez mais fundamental e decisivo na cultura contemporânea. E a arte do cinema, desde as vanguardas dos anos 20 como observa Dominique Baqué, jamais se mostrou tão impotente e inoperante diante de um mundo em crise e em sofrimento. De fato, somos bombardeados cotidianamente pelas imagens de favelados com a expressão desolada pela morte dos filhos na guerra entre o tráfico e a polícia, pelas imagens de muçulmanos indignados e enraivecidos com os cartoons dinamarqueses, com os vídeos tremidos e insituados de grupos terroristas no Iraque; 
diante desse mundo, o que pode o cineasta, o documentarista e todo realizador de imagem que não se deixa iludir diante das posturas humanistas e das formas de caridade duvidosa?

Evidentemente, esta interrogação traz o pensamento visual para o centro das questões contemporâneas, pois o que importa é saber como a imagem pode continuar a manter sua função noética, estética e política; como a imagem pode ser uma espécie de "apesar de tudo", de modo a reiterar e promover o gesto de reescrever os fatos: Gesto subjetivo, localizado, datado, declarado. Dentro desse processo amplo, a importância das tecnologias do vídeo, da internet, da televisão, é cada vez maior, na medida em que podem não só instalar-se em qualquer região ou país como também funcionam como uma espécie de conector universal dentro do global, como dispositivos de produção de real em escala planetária.

\section{Notas}

1. Dubois, Philippe. Cinema, vídeo, Godard. São Paulo: CosacNaify, 2004. Baqué, Dominique. Pour um Nouvel Art Politique: de l'Art Contemporain au Documentaire. Paris: Flammarion, 2004.

2. Para uma análise sobre o "específico" videográfico, ver Máquina e Imaginário: o Desafio das Poéticas Tecnológicas, de Arlindo Machado, São Paulo: Editora da Universidade de São Paulo, 1993, sobretudo o capítulo "Hegemonia da imagem eletrônica".

3. Nam June Paik citado em Entre-imagens, de Raymond Bellour, São Paulo: Papirus, 1997, p. 71.

4. Dubois, Idem, p. 74

5. Ao destacar e analisar a origem etimológica do termo vídeo, Dubois positiva o novo regime da imagem-técnica sem cair nas armadilhas das velhas oposições entre as antigas e as novas tecnologias. O que podemos extrair do seu brilhante estudo é que as tecnologias da imagem são acontecimentos multitemporais, acontecimentos que atuam na subjetividade e que provocam novos processos cognitivos, discursivos, afetivos, mnemônicos, tecnológicos. 
6. A partir de 1974, Godard começa a trabalhar com o vídeo, criando uma pequena empresa (Sonimage) em Grenoble, na qual trabalha como um artesão. "Descobri que há outras técnicas além do $35 \mathrm{~mm}$ (super $8,16 \mathrm{~mm}$, vídeo) que podem ser exploradas de forma pouco dispendiosa, sem no entanto opô-las ao cinema, mas ligá-las a ele". Ver "Serge Daney: o cinema como abertura para o mundo", de Andréa França, Consuelo Lins e Henri Gervaiseau, em Cinemais: revista de cinema e outras questões audiovisuais, n.15, jan/fev de 1999.

7. Citação extraída do texto de apresentação do Catálogo da Mostra Novos Rumos do Documentário Brasileiro?, que o crítico organizou dentro das atividades do $7^{\circ}$ Festival do Filme Documentário e Etnográfico de Belo Horizonte (28 de novembro a 07 de dezembro de 2003).

8. O documentário foi exibido na abertura do Festival "É TUDO VERDADE", de 2004, no Rio de Janeiro e São Paulo e teve lançamento comercial em 2005.

9. Som da rua é uma série de documentários para TV, de três minutos cada, sobre o universo sonoro que é produzido cotidianamente em diferentes regiões do Brasil. É um projeto da Produtora TVZero, na qual Berliner trabalha como diretor.

10. A pessoa é para o que nasce tem seis minutos e ganhou, entre outros prêmios, o de Melhor Documentário da Competição Brasileira, no Festival É TUDO VERDADE, de 1999.

11. O filme trabalha com vários suportes como dvcam, minidv, $16 \mathrm{~mm}$, microcâmera.

12. Comolli, Jean-Claude. "Sob o risco do Real", em Voir et Pouvoir - L'innocence perdue: cinema, télévision, fiction, documentaire. Paris: Éditions Verdier, 2004.

13. Bernardet, Jean-Claude. "A entrevista", em Cineastas e Imagens do povo. São Paulo: Companhia das Letras, 2003.

14. Comolli, Idem, Baqué, Idem.

15. Avellar, José Carlos. "Eu sou trezentos", em Cinemais-revista de cinema e outras questões audiovisuais $n^{\circ} 36$ (especial-documentário), outubro/dezembro de 2003. Ver também "O documentário performativo no Cone Sul”, de Andréa Molfetta, em Estudos de Cinema ano V, São Paulo: Panorama, 2003. 
16. Esse tema das misturas culturais está presente em Terras e fronteiras no cinema político ontemporâneo, Rio de Janeiro: ed. Faperj e 7 Letras, 2003, da autora.

17. O enquadramento é aqui tornado sensível e visível, à medida que o próprio olhar da diretora é também tema do filme. Ver a este respeito L'Epreuve du Réel à L'Écran: Essai sur le principe de réalité documentaire, de François Niney, Bruxelles: Éditions De Boeck Université, 2002, o capítulo dedicado à câmera subjetiva e ao olhar subjetivo ativo.

18. "L'Avenir du cinema", citado por Raymond Bellour em Entre-imagens, p. 320.

\section{References}

AVELLAR, José Carlos. "Eu sou trezentos", em Cinemais-revista de cinema e outras questões audiovisuaisn 36 (especial-documentário), outubro/dezembro de 2003.

BAQUÉ, Dominique. Pour um Nouvel Art Politique: de l'Art Contemporain au Documentaire. Paris: Flammarion, 2004.

BELLOUR, Raymond. Entre-imagens, São Paulo: Papirus, 1997.

BERNARDET, Jean-Claude. "A entrevista", em Cineastas e imagens do povo. São Paulo: Companhia das Letras, 2003.

. (Catálogo da Mostra Novos Rumos do Documentário Brasileiro?, do $7^{\circ}$ Festival do Filme Documentário e Etnográfico de Belo Horizonte, 2003.

COMOLLI, Jean-Claude. "Sur le risque du Réel", em Voir et Pouvoir - L'innocence perdue: cinema, télévision, fiction, documentaire. Paris: Éditions Verdier, 2004.

DUBOIS,Philippe. Cinema, vídeo, Godard. São Paulo: CosacNaify, 2004.

FRANÇA, Andrea. Terras e fronteiras no cinema político contemporâneo, Rio de Janeiro: ed. Faperj e 7 Letras, 2003.

FRANÇA, Andrea, Lins Consuelo e Gervaiseau, Henri. “Serge Daney: o cinema como abertura para o mundo", em Cinemais: revista de cinema e outras questões audiovisuais, n.15, jan/fev de 1999. 
Imagens negociadas: o experimental no cinema 163

MACHADO, Arlindo. Máquina e Imaginário: o Desafio das Poéticas Tecnológicas. São Paulo: Editora da Universidade de São Paulo, 1993.

_. (org.) Três décadas do Vídeo brasileiro. SP: Itaú Cultural, 2003.

MOLFETTA, Andrea. "O documentário performativo no Cone Sul", em Estudos de Cinema ano V, São Paulo: Panorama, 2003.

NINEY, François. L'Epreuve du Réel à L'Écran: Essai sur le principe de réalité documentaire, Bruxelles: Éditions De Boeck Université, 2002.

RANCIÈRE, Jacques. Le destin des images. Paris: La fabrique éditions, 2003. 